\title{
Socioeconomic Inequalities in the Rise of Adult Obesity: A Time-Trend Analysis of National Examination Data from Germany, 1990-2011
}

\author{
Jens Hoebel ${ }^{a}$ Benjamin Kuntz ${ }^{a}$ Lars E. Kroll ${ }^{a}$ Anja Schienkiewitz ${ }^{b}$ \\ Jonas D. Finger ${ }^{b} \quad$ Cornelia Lange ${ }^{b}$ Thomas Lampert ${ }^{a}$ \\ ${ }^{a}$ Division of Social Determinants of Health, Department of Epidemiology and Health \\ Monitoring, Robert Koch Institute, Berlin, Germany; ${ }^{\mathrm{b}}$ Division of Health Behaviour, \\ Department of Epidemiology and Health Monitoring, Robert Koch Institute, Berlin, Germany
}

\section{Keywords}

Obesity - Overweight - Social epidemiology - Social determinants - Socioeconomic factors .

Socioeconomic position

\begin{abstract}
Objective: Despite extensive study of the obesity epidemic, research on whether obesity has risen faster in lower or in higher socioeconomic groups is inconsistent. This study examined secular trends in obesity prevalence by socioeconomic position and the resulting obesity inequalities in the German adult population. Methods: Data were drawn from three national examination surveys conducted in 1990-1992, 1997-1999 and 2008-2011 ( $n=18,541$; age range: $25-69$ years). Obesity was defined by a body mass index $\geq 30 \mathrm{~kg} / \mathrm{m}^{2}$ using standardised measurements of body height and weight. Education and equivalised household disposable income were used as indicators of socioeconomic position. Time trends in socioeconomic inequalities in obesity were examined using linear probability and log-binomial regression models. Results: In each survey period, the highest socioeconomic groups had the lowest prevalence of obesity. The low and medium socioeconomic groups showed increases in obesity prevalence, whereas no such trend was observed in the high socioeconomic groups. Absolute inequalities in obesity by income increased by an average of 0.53 percentage points per year (95\% confidence interval $[\mathrm{Cl}] 0.01-1.05, p=0.047$ ) among men and 0.47 percentage points per year $(95 \% \mathrm{Cl} 0.05-0.90, p=0.029)$ among women. Absolute inequalities in obesity by education increased on average by 0.64 percentage points per year $(95 \% \mathrm{Cl} 0.19-1.08, p=$
\end{abstract}


Hoebel et al:: Socioeconomic Inequalities in Obesity Trends

0.005 ) among women but not among men ( 0.33 percentage points, $95 \% \mathrm{Cl}-0.27$ to $0.92, p=$ 0.283). Conclusions: These findings suggest a widening obesity gap between the top and the bottom of the socioeconomic spectrum. This has the potential to have adverse consequences for population health and health inequalities in coming decades. Interventions that are effective in preventing and reducing obesity in socially disadvantaged groups are needed.

(C) 2019 The Author(s)

Published by S. Karger AG, Basel

\section{Introduction}

Obesity is an independent risk factor for a variety of chronic diseases, including type 2 diabetes, cardiovascular diseases and certain cancers, and is associated with increased healthcare costs and premature death [1-7]. Worldwide, the prevalence of obesity has risen steadily over past decades [8,9], and the World Health Organization has declared obesity a "global epidemic" [10]. In many populations, especially those in high-income countries, the distribution of obesity is unequal across the socioeconomic spectrum and follows an inverse social gradient: the lower the socioeconomic position, the higher the proportion of men and women who are obese [11-17]. This finding is of great importance for social epidemiology and public health, not least as obesity and its unequal social distribution contribute substantially to the social gradient in morbidity and mortality $[18,19]$. Changes in the socioeconomic patterning of obesity can thus be an important driver for the future development of inequalities in health and longevity $[18,20]$.

Until the early 20th century, excessive body weight was widely regarded as a sign of affluence in Western societies, as only the rich could afford the food and leisure necessary to gain weight [21]. However, this has largely lost its validity given the increased access to abundant and energy-dense food for large segments of the population over the 20th century [22]. Today, medical sociologists argue that when a new health threat enters a population (such as the obesity epidemic), people in the upper socioeconomic strata are in a better position to protect themselves against it because they have the necessary resources [23]. These can include not only material resources (e.g. financial means to buy healthy foods or to pay rent in safe, physical-activity-friendly neighbourhoods) but also non-material resources, such as the ability to adopt knowledge about healthy nutrition or other weight control strategies. It can therefore be hypothesised that today's obesity epidemic may progress faster in lower than in higher socioeconomic groups. To date, however, studies have not yielded consistent results as to whether this is empirically the case [11, 13, 24-29].

Health surveys conducted regularly according to the same methodological standards allow monitoring of trends in obesity prevalence over time. Analysis of trends for different socioeconomic groups enables us to determine whether the gap in obesity between those at the top and those at the bottom of society has remained unchanged over decades, or whether it narrowed or widened during some periods. The findings of such analyses can provide clues to potential drivers of obesity inequalities, and are necessary to develop and evaluate public policies and prevention strategies, especially under "equity aspects" [13, 30]. Most available studies on trends in obesity inequalities were based on self-reported body weight and height $[11,13,24,31]$. Objective measurement data, however, are considered a more reliable alternative, even though their collection is associated with considerably greater effort and costs $[32,33]$. Recent international comparative studies on trends in obesity inequalities were mainly based on self-report data, and did not consider data from Germany, Europe's most populous country $[11,13]$. The few available time-trend studies of socioeconomic inequal- 
Hoebel et al.: Socioeconomic Inequalities in Obesity Trends

ities in obesity among German adults ended in the 1990s and considered relatively short time spans [34, 35]. In this context, the present study used standardised measurements from national health examination surveys to investigate secular trends in the socioeconomic patterning of obesity among men and women in Germany from 1990 to 2011.

\section{Methods}

\section{Study Design}

The time-trend analysis was based on three German national health examination surveys conducted in 1990-1992, 1997-1999 and 2008-2011 ( $n=18,541$; age range: $25-69$ years). These surveys are part of the German health monitoring system administered by the Robert Koch Institute (RKI) on behalf of the German Federal Ministry of Health. In each survey, a twostage cluster sampling procedure was used to recruit a national sample of adults with permanent residence in Germany. In the first sampling stage, 120-180 municipalities were randomly selected from a list of all German municipalities, stratified by region and urbanisation. In the second stage, people with their principal residence in the sampled municipalities were randomly drawn from local population registers. Identified subjects were invited to temporary study centres located in the sampled municipalities. At these study centres, data were collected by physical examinations, collection of biological samples, personal interviews and self-administered questionnaires. Further information about sampling, response rates and data collection has been published elsewhere in more detail [36-39].

\section{Measures}

The participants underwent physical examinations by trained healthcare personnel at the localstudy centres. The standardised examinationsincluded anthropometric measurement of standing height (m) and body weight (kg). For the 18,541 participants, body mass index (BMI) was calculated as the ratio of weight to height squared $\left(\mathrm{kg} / \mathrm{m}^{2}\right)$. Adult obesity was defined as a BMI $\geq 30 \mathrm{~kg} / \mathrm{m}^{2}$ according to World Health Organization recommendations [40].

Socioeconomic position was determined by participants' education and income. Using the International Standard Classification of Education (ISCED), the participants were assigned to three educational levels: low (ISCED level 1-2: primary or low secondary education), medium (ISCED level 3-4: upper secondary or post-secondary, non-tertiary education) and high (ISCED level 5-6: tertiary education). The ISCED classification considers both the highest school level completed and the highest professional qualification attained [41]. Income level was assessed by equivalised household disposable income (terciles), calculated by dividing the total disposable income of each participant's household by the square root of the number of household members [42]. Income equivalisation takes into account that the needs of a household (e.g. housing, electricity) do not increase proportionally with each additional household member because of the cost-saving effects that arise when multiple persons act as an economic unit.

\section{Statistical Analysis}

Obesity prevalence was estimated for each survey period, stratified by sex, education and income. For each period and stratum, the prevalence was age standardised to the 2013 European Standard Population [43] to control for demographic changes and differences in age distribution between the groups. Time trends were examined with logistic regression models, regressing obesity on the time when the survey was conducted.

Socioeconomic inequalities in obesity were analysed using simple measures of group differences (prevalence difference [PD], prevalence ratio [PR]) and complex summary 
Hoebel et al.: Socioeconomic Inequalities in Obesity Trends

Table 1. Characteristics of the study population

\begin{tabular}{lccc}
\hline & $\begin{array}{c}1990-1992 \\
(n=7,410)\end{array}$ & $\begin{array}{c}1997-1999 \\
(n=5,790)\end{array}$ & $\begin{array}{l}2008-2011 \\
(n=5,341)\end{array}$ \\
\hline $\begin{array}{l}\text { Sex, \% }(n) \\
\quad \text { Male }\end{array}$ & $49.0(3,608)$ & $50.6(2,820)$ & $50.3(2,524)$ \\
$\quad$ Female & $51.0(3,802)$ & $49.4(2,970)$ & $49.7(2,817)$ \\
Age, years & & & \\
$\quad$ Range & $25-69$ & $25-69$ & $25-69$ \\
$\quad$ Mean \pm SD & $45.2 \pm 12.9$ & $45.3 \pm 12.6$ & $46.8 \pm 12.2$ \\
Education, \% $(n)$ & & & $16.1(550)$ \\
$\quad$ Low & $22.3(1,481)$ & $54.9(3,232)$ & $56.4(2,843)$ \\
$\quad$ Medium & $55.8(4,158)$ & $23.7(1,572)$ & $27.6(1,915)$ \\
$\quad$ High & $22.0(1,770)$ & $33.5(1,939)$ & $35.0(1,763)$ \\
Income tercile, \% $(n)$ & $33.3(2,615)$ & $33.8(1,999)$ & $32.0(1,721)$ \\
$\quad$ Low & $33.4(2,448)$ & $32.7(1,852)$ & $33.0(1,857)$ \\
$\quad$ Medium & $33.3(2,318)$ & $26.9 \pm 4.7$ & $27.0 \pm 5.1$ \\
$\quad$ High & & & \\
Body mass index, $\mathrm{kg} / \mathrm{m}^{2}$ & $26.6 \pm 4.6$ & & \\
$\quad$ Mean \pm SD & & & \\
\hline
\end{tabular}

$\%$, weighted percentage (adjustment for non-response); $n$, unweighted number of observations; SD, standard deviation.

measures of inequality (slope index of inequality [SII], relative index of inequality [RII]). PDs and SIIs quantify the magnitude of absolute inequality, and PRs and RIIs represent the magnitude of relative inequality. Selective use of exclusively absolute or relative measures of inequality can lead to a biased assessment of increasing or decreasing health inequalities over time; thus it is recommended that both be considered when possible $[44,45]$.

The SII and RII are regression-based measures that consider the entire distribution of a socioeconomic variable and the size of the socioeconomic groups $[44,46]$. Linear probability models were used to calculate the SII, whereas log-binomial models were used to compute the RII. Changes in the size of the socioeconomic groups over time were taken into account by computing "ridit" scores of the socioeconomic variables for each survey. Accordingly, ridit analysis [47] was used to convert the categorical education and income variables for each survey to reverse fractional rank variables ranging from 0 (most education or income) to 1 (least education or income). In this process, each socioeconomic group was given a score based on the midpoint of its range in the cumulative distribution in the population. These ridit scores were then entered into the regression models as independent variables $[47,48]$. Since ridit scores of a socioeconomic variable reflect relative ranks in the socioeconomic distribution, they must be interpreted as a measure of relative socioeconomic position. The resulting SII (RII) indicates the rate difference (rate ratio) between people at the very bottom and those at the very top of the socioeconomic spectrum. Time trends in SII and RII were analysed by adding an interaction term between socioeconomic position (fractional rank variable) and year to the models, while adjusting for age, age $\times$ year, residential region (East vs. West Germany) and the main effects of socioeconomic position and year.

Weighting factors were used to account for unequal sampling probabilities and adjust the distribution of each sample by sex, age, education and region, to match official German population statistics. All analyses were performed using Stata version 14.2 (StataCorp LP, College Station, TX, USA) survey data commands, taking account of weighting and the cluster design. 
Hoebel et al.: Socioeconomic Inequalities in Obesity Trends

Table 2. Age-standardised prevalence of obesity among adults aged 25-69 years in Germany

\begin{tabular}{|c|c|c|c|c|}
\hline & $\begin{array}{l}1990-1992, \\
\%^{\mathrm{a}}(95 \% \mathrm{CI})\end{array}$ & $\begin{array}{l}\text { 1997-1999, } \\
\%^{\mathrm{a}}(95 \% \mathrm{CI})\end{array}$ & $\begin{array}{l}2008-2011 \\
\%^{\mathrm{a}}(95 \% \mathrm{CI})\end{array}$ & $p$ trend \\
\hline \multicolumn{5}{|l|}{ Men } \\
\hline Total & $19.1(17.4-20.9)$ & $21.2(19.5-23.1)$ & $24.6(22.2-27.1)$ & $<0.001$ \\
\hline \multicolumn{5}{|l|}{ Education } \\
\hline Low & $22.8(18.3-28.0)$ & $23.2(19.1-27.8)$ & $29.4(22.0-38.0)$ & 0.163 \\
\hline Medium & $20.4(18.4-22.7)$ & $23.2(20.8-25.8)$ & $26.5(23.1-30.3)$ & 0.003 \\
\hline High & $14.8(12.1-17.8)$ & $16.8(14.5-19.4)$ & 18.7 (15.9-21.8) & 0.061 \\
\hline \multicolumn{5}{|l|}{ Income } \\
\hline Low & $20.4(17.5-23.6)$ & $24.3(21.2-27.8)$ & $28.3(24.4-32.6)$ & 0.002 \\
\hline Medium & $21.4(18.5-24.6)$ & $23.4(20.3-26.8)$ & $27.6(23.7-31.8)$ & 0.015 \\
\hline High & $16.0(14.0-18.3)$ & $16.6(14.2-19.2)$ & $17.6(14.5-21.3)$ & 0.436 \\
\hline \multicolumn{5}{|l|}{ Women } \\
\hline Total & 21.6 (19.9-23.3) & $23.7(21.5-26.0)$ & $23.0(20.9-25.3)$ & 0.329 \\
\hline \multicolumn{5}{|l|}{ Education } \\
\hline Low & 28.7 (25.7-31.8) & $34.3(29.5-39.5)$ & $35.2(28.9-41.9)$ & 0.047 \\
\hline Medium & 19.5 (17.3-21.8) & $21.8(19.3-24.4)$ & $23.2(20.7-26.0)$ & 0.035 \\
\hline High & $14.6(11.2-18.7)$ & $11.7(8.3-16.3)$ & $10.9(8.6-13.6)$ & 0.113 \\
\hline \multicolumn{5}{|l|}{ Income } \\
\hline Low & $27.2(24.7-29.8)$ & $29.5(26.0-33.2)$ & $30.1(26.5-34.1)$ & 0.206 \\
\hline Medium & $22.0(19.6-24.5)$ & $23.2(20.1-26.6)$ & $21.9(19.0-25.1)$ & 0.943 \\
\hline High & 13.7 (11.4-16.3) & $17.9(15.3-20.8)$ & $15.0(12.5-18.0)$ & 0.584 \\
\hline
\end{tabular}

CI, confidence interval. ${ }^{\text {a }}$ Age-standardised to the 2013 European Standard Population.

\section{Results}

Table 1 presents the characteristics of the study population. The mean age, mean BMI and share of people with a high educational level increased across the surveys. The crude prevalence of obesity increased from 19.7\% (95\% confidence interval [CI] 18.5-21.0) in 19901992 to $21.7 \%$ (95\% CI 20.1-23.4) in 1997-1999 and 23.7\% (95\% CI 22.1-25.4) in 20082011 ( $p$ trend $<0.001$ ).

Table 2 shows the age-standardised prevalence of obesity and sex-specific trends over time for the different socioeconomic groups. In each survey period, obesity was least prevalent in the highest socioeconomic groups. Among men, the prevalence increased in the low and medium socioeconomic groups but remained largely constant in the high socioeconomic groups. This was especially evident with regard to income. Among women, the pattern of increasing obesity rates in low and medium socioeconomic groups was observed for education but not for income.

Table 3 presents the measures of absolute inequalities in obesity. From 1990-1992 to 2008-2011, the age-standardised PD between the lowest and the highest income tercile increased among men. This trend was also reflected in the SII. The linear probability models estimated that absolute income inequalities increased by an average of 0.53 percentage points per year (95\% CI $0.01-1.05$ ) in male obesity and by an average of 0.47 percentage points per year (95\% CI 0.05-0.90) in female obesity in the period from 1990-1992 to 20082011. With regard to education, the age-standardised PD between women with low and those with high education increased over the study period. The linear probability models revealed an average increase in absolute educational inequalities in female obesity by 0.64 percentage points per year ( $95 \%$ CI $0.19-1.08)$, a trend not evident among men ( 0.33 percentage points per year, $95 \%$ CI -0.27 to 0.92 ). 
Hoebel et al.: Socioeconomic Inequalities in Obesity Trends

Table 3. Absolute inequalities in obesity by education and income among adults aged 25-69 years in Germany

\begin{tabular}{|c|c|c|c|c|}
\hline & 1990-1992 & 1997-1999 & 2008-2011 & $p$ trend \\
\hline \multicolumn{5}{|l|}{ Men } \\
\hline \multicolumn{5}{|l|}{ Education } \\
\hline \multicolumn{5}{|l|}{$\mathrm{PD}^{\mathrm{a}}(95 \% \mathrm{CI})$} \\
\hline Low education & $8.0(2.1-14.0)$ & $6.3(1.3-11.4)$ & 10.7 (1.7-19.7) & 0.643 \\
\hline Medium education & $5.7(2.3-9.0)$ & $6.4(3.3-9.5)$ & $7.9(3.4-12.4)$ & 0.421 \\
\hline High education (Ref.) & 0.0 & 0.0 & 0.0 & \\
\hline $\operatorname{SII}^{\mathrm{b}}(95 \% \mathrm{CI})$ & $0.11(0.05-0.18)$ & $0.10(0.04-0.16)$ & $0.17(0.08-0.26)$ & 0.283 \\
\hline \multicolumn{5}{|l|}{ Income } \\
\hline \multicolumn{5}{|l|}{$\mathrm{PD}^{\mathrm{a}}(95 \% \mathrm{CI})$} \\
\hline Low income & $4.3(0.7-8.0)$ & $7.8(3.7-11.9)$ & 10.7 (5.7-15.7) & 0.046 \\
\hline Medium income & $5.3(1.9-8.8)$ & $6.9(2.8-10.9)$ & $10.0(4.6-15.3)$ & 0.152 \\
\hline High income (Ref.) & 0.0 & 0.0 & 0.0 & \\
\hline $\operatorname{SII}^{\mathrm{b}}(95 \% \mathrm{CI})$ & $0.07(0.01-0.12)$ & $0.10(0.03-0.16)$ & $0.16(0.08-0.24)$ & 0.047 \\
\hline \multicolumn{5}{|l|}{ Women } \\
\hline \multicolumn{5}{|l|}{ Education } \\
\hline \multicolumn{5}{|l|}{$\mathrm{PD}^{\mathrm{a}}(95 \% \mathrm{CI})$} \\
\hline Low education & $14.1(9.4-18.8)$ & $22.6(16.0-29.3)$ & $24.3(17.4-31.2)$ & 0.012 \\
\hline Medium education & $4.9(0.8-9.1)$ & $10.1(6.0-14.2)$ & $12.4(8.7-16.0)$ & 0.009 \\
\hline High education (Ref.) & 0.0 & 0.0 & 0.0 & \\
\hline $\operatorname{SII}^{\mathrm{b}}(95 \% \mathrm{CI})$ & $0.18(0.14-0.23)$ & $0.27(0.20-0.34)$ & $0.30(0.23-0.36)$ & 0.005 \\
\hline \multicolumn{5}{|l|}{ Income } \\
\hline \multicolumn{5}{|l|}{$\mathrm{PD}^{\mathrm{a}}(95 \% \mathrm{CI})$} \\
\hline Low income & $13.5(10.4-16.7)$ & $11.6(7.8-15.4)$ & 15.1 (10.5-19.7) & 0.531 \\
\hline Medium income & $8.3(5.1-11.5)$ & $5.3(1.3-9.4)$ & $6.9(3.0-10.8)$ & 0.643 \\
\hline High income (Ref.) & 0.0 & 0.0 & 0.0 & \\
\hline $\operatorname{SII}^{\mathrm{b}}(95 \% \mathrm{CI})$ & $0.14(0.10-0.18)$ & $0.16(0.11-0.22)$ & $0.23(0.16-0.29)$ & 0.029 \\
\hline
\end{tabular}

PD, prevalence difference (in percentage points); SII, slope index of inequality; CI, confidence interval; Ref., reference group. ${ }^{\text {a }}$ Age-standardised to the 2013 European Standard Population. ${ }^{\text {b }}$ Adjusted for age and residential region.

Table 4 provides the measures of relative inequalities in obesity. On the relative scale, inequalities in obesity existed across all survey periods. For males, the relative inequalities in obesity did not change substantially over time, but the PR of obesity among women with low versus those with high education increased from 1.97 in 1990-1992 to 3.23 in 20082011.

\section{Discussion}

To our knowledge, this is the first study to examine socioeconomic inequalities in the obesity epidemic among Germany's adult population over a period of two decades since German reunification. The examination data from three national health surveys showed rising obesity rates in the low and middle socioeconomic groups, whereas no such trend was evident in the upper socioeconomic strata. The absolute gap in obesity between the top and the bottom of the socioeconomic spectrum widened between 1990 and 2011, particularly with rising obesity rates among men with a lower income and women with a lower education level. These findings indicate that the adult obesity epidemic in Germany has largely been restricted to the middle and lower end of the socioeconomic spectrum. 
Hoebel et al.: Socioeconomic Inequalities in Obesity Trends

Table 4. Relative inequalities in obesity by education and income among adults aged 25-69 years in Germany

\begin{tabular}{|c|c|c|c|c|}
\hline & 1990-1992 & 1997-1999 & 2008-2011 & $p$ trend \\
\hline \multicolumn{5}{|l|}{ Men } \\
\hline \multicolumn{5}{|l|}{ Education } \\
\hline \multicolumn{5}{|l|}{$\mathrm{PR}^{\mathrm{a}}(95 \% \mathrm{CI})$} \\
\hline Low education & $1.54(1.14-2.10)$ & $1.38(1.08-1.75)$ & $1.57(1.12-2.21)$ & 0.888 \\
\hline Medium education & $1.38(1.13-1.70)$ & $1.38(1.17-1.62)$ & $1.42(1.16-1.74)$ & 0.808 \\
\hline High education (Ref.) & 1.00 & 1.00 & 1.00 & \\
\hline RII $^{\mathrm{b}}(95 \% \mathrm{CI})$ & $1.79(1.26-2.55)$ & 1.49 (1.13-1.97) & $1.85(1.29-2.64)$ & 0.788 \\
\hline \multicolumn{5}{|l|}{ Income } \\
\hline \multicolumn{5}{|l|}{$\mathrm{PR}^{\mathrm{a}}(95 \% \mathrm{CI})$} \\
\hline Low income & $1.27(1.04-1.55)$ & $1.47(1.20-1.80)$ & $1.61(1.28-2.02)$ & 0.137 \\
\hline Medium income & $1.33(1.11-1.60)$ & $1.41(1.16-1.73)$ & $1.57(1.23-2.00)$ & 0.302 \\
\hline High income (Ref.) & 1.00 & 1.00 & 1.00 & \\
\hline $\mathrm{RII}^{\mathrm{b}}(95 \% \mathrm{CI})$ & $1.40(1.06-1.85)$ & $1.68(1.27-2.22)$ & $1.77(1.30-2.41)$ & 0.294 \\
\hline \multicolumn{5}{|l|}{ Women } \\
\hline \multicolumn{5}{|l|}{ Education } \\
\hline \multicolumn{5}{|l|}{$\mathrm{PR}^{\mathrm{a}}(95 \% \mathrm{CI})$} \\
\hline Low education & $1.97(1.50-2.59)$ & $2.94(2.01-4.29)$ & $3.23(2.42-4.32)$ & 0.014 \\
\hline Medium education & $1.34(1.02-1.75)$ & $1.86(1.34-2.58)$ & $2.14(1.65-2.76)$ & 0.019 \\
\hline High education (Ref.) & 1.00 & 1.00 & 1.00 & \\
\hline $\operatorname{RII}^{\mathrm{b}}(95 \% \mathrm{CI})$ & $2.62(1.94-3.53)$ & $3.35(2.31-4.87)$ & $4.02(2.92-5.55)$ & 0.060 \\
\hline \multicolumn{5}{|l|}{ Income } \\
\hline \multicolumn{5}{|l|}{$\mathrm{PR}^{\mathrm{a}}(95 \% \mathrm{CI})$} \\
\hline Low income & $1.99(1.66-2.39)$ & $1.65(1.40-1.95)$ & $2.01(1.61-2.49)$ & 0.803 \\
\hline Medium income & $1.61(1.32-1.95)$ & 1.30 (1.07-1.58) & $1.46(1.17-1.81)$ & 0.609 \\
\hline High income (Ref.) & 1.00 & 1.00 & 1.00 & \\
\hline $\mathrm{RII}^{\mathrm{b}}(95 \% \mathrm{CI})$ & 2.18 (1.74-2.73) & $1.91(1.50-2.44)$ & $2.75(2.05-3.71)$ & 0.185 \\
\hline
\end{tabular}

PR, prevalence ratio; RII, relative index of inequality; CI, confidence interval; Ref., reference group. ${ }^{a}$ Age-standardised to the 2013 European Standard Population. ${ }^{\text {b }}$ Adjusted for age and residential region.

\section{Comparisons with Previous Research}

Our results support previous findings from several European countries that absolute socioeconomic inequalities in obesity have widened over the past decades, while relative obesity inequalities have largely persisted [13, 24, 25, 49]. Moreover, empirical results suggesting the obesity epidemic has progressed faster in lower socioeconomic groups have been reported for countries neighbouring Germany, such as Austria, Switzerland and France $[24,31,50]$. There is, however, also evidence from Europe and other high-income countries to suggest that obesity has risen equally across the socioeconomic spectrum or even more strongly in higher socioeconomic groups, concomitant with constant or narrowing relative obesity inequalities over time [11, 26-28, 51, 52]. Data from the US national health examination surveys revealed that over the course of three decades since the 1970s, obesity increased at all educational and income levels, and that, typically, it was not the most deprived who experienced the largest gains $[26,52]$. Our findings and those from previous studies demonstrate that the socioeconomic patterning of adult obesity is a dynamic phenomenon, and that these dynamics vary across time and space. The present findings contribute to filling the research gap for Germany in that this study was the first to examine time trends in socioeconomic obesity inequalities since German reunification beyond the turn of the millennium. Previous German trend studies on socioeconomic obesity inequalities ended in the 1990s and covered much shorter periods of less than a decade [34, 35]. This may also be one reason why no marked changes in socioeconomic obesity inequalities were found in the 
previous studies. Moreover, the previous studies considered only education as a measure of socioeconomic position. As our findings show, educational and income inequalities in obesity do not necessarily correspond in their trends over time. The consideration of both socioeconomic position dimensions thus provides a more comprehensive picture of the phenomenon under study.

It has been argued that the reasons for a larger increase in obesity among lower socioeconomic groups must be that these groups are either more exposed to obesogenic factors or more vulnerable to their effects [13]. With regard to exposure, research from Germany suggests that people who are socioeconomically deprived live in neighbourhoods with greater access to fast-food outlets [53]. Similar findings have been reported from Canada, the UK or Australia [54-57]. Residents in deprived areas are therefore more likely to have obesogenic dietary intakes than those in advantaged areas [58]. However, there is conflicting evidence and some controversy regarding whether people with a low socioeconomic position have poorer diets and are more obese because they live in more obesogenic environments [59,60]. For Germany, there is evidence from the city of Kiel to suggest that a higher neighbourhood-level density of stores selling energy-dense food (e.g. fast-food restaurants, takeaways) is associated with a higher individual BMI among adolescent residents, although with a relatively small effect size [61]. A study from Berlin found a higher district-level density of fast-food restaurants to be associated with overweight and obesity in preschool children [62]; however, the association was not very robust and the Berlin districts are relatively large spatial units. Research is still needed on the effects of environmental characteristics on adult weight status in Germany and how these contribute to trends in socioeconomic obesity inequalities. Assuming that obesogenic effects of environmental factors do exist, one can suppose that socially disadvantaged people may have the least access to resources required to cope with and protect themselves against the threats of an obesogenic environment, which is likely to make them more prone to its effects. These resources include not only money to afford healthy foods, but also nonmaterial resources such as cultural capital, health literacy and food literacy [63-65].

In addition to food supply and diet, physical activity is an important part of the energy expenditure-weight equation. Over recent decades, leisure-time physical exercise has increased among adults in Germany [36], but only in higher socioeconomic groups [66]. This might have contributed to preventing obesity in these segments of the population. Environmental factors may again play an important role, as residents in deprived neighbourhoods face more environmental barriers to being physically active [67]. Furthermore, healthy eating and leisure-time physical activity can both be considered behavioural expressions of a cultural habitus that is today typical for high socioeconomic groups, and may increasingly be practiced by socially advantaged people to distinguish themselves from lower socioeconomic groups $[63,68]$.

\section{Strengths and Limitations}

The present analysis was based on large national samples, which enabled separate analyses for men and women. The sample design and weighting factors used to adjust for nonresponse make it possible to draw conclusions for Germany's population aged 25-69 years from our results. The use of internationally established methods, such as the ISCED, European Standard Population, SII and RII, will also allow our results to be used for cross-country comparisons or future meta-analyses. The BMI was obtained from standardised anthropometric measurements, which have the advantage over self-reported height and weight in that they are more reliable and less prone to information bias [32, 33].

Despite these strengths, this study has some limitations worth mentioning. Generally, causality between socioeconomic position and obesity cannot be inferred, because of the observational and cross-sectional nature of the data; evidence suggests the relationship is likely to be bidirectional [69]. Further, even though BMI has a high sensitivity to predict high 
fat mass and is probably the most important measure of relative adipose tissue in population studies and clinical practice, it may provide misleading information about body fat content owing to relatively poor specificity for this phenotype [70,71]. Moreover, the present study only considered general obesity status and not obesity severity. A recent US study indicated that trends in obesity inequalities can be stronger for obesity severity than for general obesity status [72]. However, this question was beyond the scope of our analysis. In addition, the question of whether obesity trends followed a non-linear rather than a linear pattern was beyond the scope of this study. As in many previous trend studies [13,31,73-75], we assumed linear trends. Future studies, preferably those with a data series of more than three data points $[49,76]$, could assess whether this assumption holds true.

\section{Implications for Policy and Practice}

Our findings highlight the need for policies and interventions that are effective in preventing and reducing obesity, especially in lower socioeconomic groups. Recently, Bambra et al. [77] systematically reviewed the evidence on the effectiveness of interventions to reduce socioeconomic inequalities in obesity. Their results showed that individual-level health education interventions had little long-term effect on weight outcomes in high or in low socioeconomic groups. The impact of such interventions on socioeconomic inequalities in obesity is therefore likely to be small and short-lived. For community-level interventions, those authors found evidence that community-based group interventions for adults, such as diet clubs or behavioural programmes, had short-term but no longer-term effects on weight loss in low socioeconomic groups or equally across socioeconomic groups. However, when started atyounger ages, school-based nutrition and physical activity education programmes combined with exercise sessions can be effective in the longer term in lower socioeconomic groups. Only a few studies had evaluated more upstream interventions at the societal level. As emphasised by Bambra et al. [77], this does not provide evidence for a lack of effectiveness, but rather a lack of evaluation evidence for this type of intervention. Therefore, they pointed to a need for more scientific evaluations of the effects of interventions in reducing socioeconomic inequalities in obesity, particularly in terms of society-level interventions (e.g. taxes on high-fat foods or bans on fast-food advertising). A recent systematic review suggested that a tax on sugar-sweetened beverages will deliver similar population weight benefits across socioeconomic groups or greater benefits for lower socioeconomic groups [78]. This is generally supported by another review that found evidence for upstream interventions (e.g. tax-related fiscal measures) to have neutral or positive impacts on inequalities in anthropometric outcomes [79]. Nonetheless, more evaluation research is needed to better understand which upstream interventions work across the entire socioeconomic spectrum and especially in lower socioeconomic groups. Recent policy implementations in some countries, such as a sugar tax on soft drinks, should be monitored scientifically to gain more detailed knowledge about their effects at the population level and in population subgroups. In the sense of natural experiments, for instance, trends in countries with policy implementation could be compared with trends in other, similar countries without such policy as control groups. In this respect, our study underlines once again that obesity trends should be examined not only at the wholepopulation level, but also in different socioeconomic groups.

\section{Conclusions}

The findings of this study indicate that obesity has reached epidemic proportions in groups at the middle and bottom of the socioeconomic spectrum of Germany's adult population. This has the potential to have far-reaching consequences for population health and 
health inequalities in Europe's most populous country, especially as obesity is a leading cause of morbidity and mortality and an important contributor to the social gradient in health. Further research is needed to better understand tangible drivers of the obesity epidemic and to empirically explain why obesity tends to rise faster among relatively disadvantaged groups in Germany. Cross-country comparative studies and natural experiments might be helpful in order to make further progress in this field. The findings may contribute to developing policies and interventions that are effective in preventing and reducing obesity in relevant population subgroups, which is essential to counteract the possible public health consequences of the socially unequal rise in obesity prevalence.

\section{Acknowledgements}

The authors would like to thank the study participants and all employees of the RKI who helped conduct the surveys. Special thanks are due to Lisa Bührmann and Julia Rehling for their thorough support in the search of literature. We also thank Audrey Holmes for editing a draft of this manuscript.

\section{Statement of Ethics}

The 2008-2011 survey was approved by the local ethics committee at Charite - Universitätsmedizin Berlin (application No. EA2/047/08). The 1997-1999 and 2008-2011 surveys conform to the principles of the Helsinki Declaration. All participants were informed about the study objectives and data protection. The participants in the 1997-1999 and 2008-2011 surveys provided written informed consent prior to participation. The surveys were conducted according to the guidelines of the Federal and State Commissioners for Data Protection.

\section{Disclosure Statement}

The authors note no conflicts of interest.

\section{Funding Sources}

This work was supported by the RKI and the German Federal Ministry of Health (BMG).

\section{Author Contributions}

J.H. reviewed the literature, performed the statistical analyses and drafted the first version of the manuscript. L.E.K. contributed to the statistical analysis. J.D.F., B.K., A.S. and C.L. reviewed the manuscript critically. T.L. supervised the study and reviewed the manuscript critically. All authors contributed to interpretation of findings, and reviewed, edited and approved the final manuscript. 
Hoebel et al.: Socioeconomic Inequalities in Obesity Trends

\section{References}

1 Abdullah A, Peeters A, de Courten M, Stoelwinder J. The magnitude of association between overweight and obesity and the risk of diabetes: a meta-analysis of prospective cohort studies. Diabetes Res Clin Pract. 2010 Sep;89(3):309-19.

2 Guh DP, Zhang W, Bansback N, Amarsi Z, Birmingham CL, Anis AH. The incidence of co-morbidities related to obesity and overweight: a systematic review and meta-analysis. BMC Public Health. 2009 Mar;9(1):88.

3 World Cancer Research Fund. American Institute for Cancer Reseach: Food, Nutrition, Physical Activity and the Prevention of Cancer: A Global Perspective. Washington (DC): AICR; 2007.

4 von Lengerke T, John J, Mielck A; KORA Study Group. Excess direct medical costs of severe obesity by socioeconomic status in German adults. Psychosoc Med. 2010 Apr; 7:Doc01.

5 Effertz T, Engel S, Verheyen F, Linder R. The costs and consequences of obesity in Germany: a new approach from a prevalence and life-cycle perspective. Eur J Health Econ. 2016 Dec;17(9):1141-58.

6 Carmienke S, Freitag MH, Pischon T, Schlattmann P, Fankhaenel T, Goebel H, et al. General and abdominal obesity parameters and their combination in relation to mortality: a systematic review and meta-regression analysis. Eur J Clin Nutr. 2013 Jun;67(6):573-85.

7 Flegal KM, Kit BK, Orpana H, Graubard BI. Association of all-cause mortality with overweight and obesity using standard body mass index categories: a systematic review and meta-analysis. JAMA. 2013 Jan;309(1):71-82.

8 Abarca-Gómez L, Abdeen ZA, Hamid ZA, Abu-Rmeileh NM, Acosta-Cazares B, Acuin C, et al.; NCD Risk Factor Collaboration (NCD-RisC). Worldwide trends in body-mass index, underweight, overweight, and obesity from 1975 to 2016: a pooled analysis of 2,416 population-based measurement studies in 128.9 million children, adolescents, and adults. Lancet. 2017 Dec;390(10113):2627-42.

9 Ng M, Fleming T, Robinson M, Thomson B, Graetz N, Margono C, et al. Global, regional, and national prevalence of overweight and obesity in children and adults during 1980-2013: a systematic analysis for the Global Burden of Disease Study 2013. Lancet. 2014 Aug;384(9945):766-81.

10 World Health Organization. Obesity: Preventing and Managing the Global Epidemic. Geneva: WHO; 2000.

11 Devaux M, Sassi F. Social inequalities in obesity and overweight in 11 OECD countries. Eur J Public Health. 2013 Jun;23(3):464-9.

12 Sobal J, Stunkard AJ. Socioeconomic status and obesity: a review of the literature. Psychol Bull. 1989 Mar; 105(2):260-75.

13 Hoffmann K, De Gelder R, Hu Y, Bopp M, Vitrai J, Lahelma E, et al. Trends in educational inequalities in obesity in 15 European countries between 1990 and 2010. Int J Behav Nutr Phys Act. 2017 May;14(1):63.

14 Mackenbach JP, Stirbu I, Roskam AJ, Schaap MM, Menvielle G, Leinsalu M, et al.; European Union Working Group on Socioeconomic Inequalities in Health. Socioeconomic inequalities in health in 22 European countries. N Engl J Med. 2008 Jun;358(23):2468-81.

15 Kuntz B, Lampert T. Socioeconomic factors and obesity. Dtsch Arztebl Int. 2010 Jul;107(30):517-22.

16 Roskam AJ, Kunst AE, Van Oyen H, Demarest S, Klumbiene J, Regidor E, et al.; for additional participants to the study. Comparative appraisal of educational inequalities in overweight and obesity among adults in 19 European countries. Int J Epidemiol. 2010 Apr;39(2):392-404.

17 McLaren L. Socioeconomic status and obesity. Epidemiol Rev. 2007;29(1):29-48.

18 Hoffmann R, Eikemo TA, Kulhánová I, Kulik MC, Looman C, Menvielle G, et al. Obesity and the potential reduction of social inequalities in mortality: evidence from 21 European populations. Eur J Public Health. 2015 Oct;25(5):849-56.

19 Kulhánová I, Menvielle G, Hoffmann R, Eikemo TA, Kulik MC, Toch-Marquardt M, et al. The role of three lifestyle risk factors in reducing educational differences in ischaemic heart disease mortality in Europe. Eur J Public Health. 2017;27(2):203-10.

20 Mackenbach JP. What would happen to health inequalities if smoking were eliminated? BMJ. 2011 Jun; 342:d3460.

21 Jeffcoate W. Obesity is a disease: food for thought. Lancet. 1998 Mar;351(9106):903-4.

22 Levenstein HA. Revolution at the table: the transformation of the American diet. New York: Oxford University Press; 1988.

23 Miech R, Pampel F, Kim J, Rogers RG. The enduring association between education and mortality: the role of widening and narrowing disparities. Am Sociol Rev. 2011 Dec;76(6):913-34.

24 Singh-Manoux A, Gourmelen J, Lajnef M, Sabia S, Sitta R, Menvielle G, et al. Prevalence of educational inequalities in obesity between 1970 and 2003 in France. Obes Rev. 2009 Sep;10(5):511-8.

25 Krokstad S, Ernstsen L, Sund ER, Bjørngaard JH, Langhammer A, Midthjell K, et al. Social and spatial patterns of obesity diffusion over three decades in a Norwegian county population: the HUNT Study. BMC Public Health. 2013 Oct; 13(1):973.

26 Chang VW, Lauderdale DS. Income disparities in body mass index and obesity in the United States, 1971-2002. Arch Intern Med. 2005 Oct;165(18):2122-8.

27 Lahti-Koski M, Seppänen-Nuijten E, Männistö S, Härkänen T, Rissanen H, Knekt P, et al. Twenty-year changes in the prevalence of obesity among Finnish adults. Obes Rev. 2010 Mar;11(3):171-6.

28 Zhu J, Coombs N, Stamatakis E. Temporal trends in socioeconomic inequalities in obesity prevalence among economically-active working-age adults in Scotland between 1995 and 2011: a population-based repeated cross-sectional study. BMJ Open. 2015 Jun;5(6):e006739. 
Hoebel et al.: Socioeconomic Inequalities in Obesity Trends

29 Pérez-Ferrer C, Jaccard A, Knuchel-Takano A, Retat L, Brown M, Kriaucioniene V, et al. Inequalities in smoking and obesity in Europe predicted to 2050: findings from the EConDA project. Scand J Public Health. 2018 Jul;46(5):530-40.

30 Kumanyika S. Getting to equity in obesity prevention: a new framework. Washington (DC): National Academy of Medicine; 2017.

31 Großschädl F, Stronegger WJ. Long-term trends in obesity among Austrian adults and its relation with the social gradient: 1973-2007. Eur J Public Health. 2013 Apr;23(2):306-12.

32 Hill A, Roberts J. Body mass index: a comparison between self-reported and measured height and weight. J Public Health Med. 1998 Jun;20(2):206-10.

33 Connor Gorber S, Tremblay M, Moher D, Gorber B. A comparison of direct vs. self-report measures for assessing height, weight and body mass index: a systematic review. Obes Rev. 2007 Jul;8(4):307-26.

34 Icks A, Moebus S, Feuersenger A, Haastert B, Jöckel KH, Mielck A, et al. Widening of a social gradient in obesity risk? German national health surveys 1990 and 1998. Eur J Epidemiol. 2007;22(10):685-90.

35 Heinemann L, Helmert U, Classen E, Greiser E. Social gradient of CVD risk in Germany before/after unification. Rev Environ Health. 1996 Jan-Jun;11(1-2):7-14.

36 Finger JD, Busch MA, Du Y, Heidemann C, Knopf H, Kuhnert R, et al. Time trends in cardiometabolic risk factors in adults: results from three nationwide German examination surveys from 1990-2011. Dtsch Arztebl Int. 2016 Oct;113(42):712-9.

37 Scheidt-Nave C, Kamtsiuris P, Gößwald A, Hölling H, Lange M, Busch MA, et al. German health interview and examination survey for adults (DEGS) - design, objectives and implementation of the first data collection wave. BMC Public Health. 2012 Sep;12(1):730-730.

38 Schaefer H. [Address: on the diagnostic power of demographic data]. 1999 Feb;61(2):57-61. [In German].

39 von Troschke J, Klaes L, Maschewsky-Schneider U, Scheuermann W. Die Deutsche Herz-Kreislauf-Präventionsstudie: Design und Ergebnisse. Bern: Huber; 1998.

40 WHO Global InfoBase Team. The SuRF Report 2 - Surveillance of chronic disease risk factors: country-level data and comparable estimates. Geneva: World Health Organization; 2005.

41 Organisation for Economic Co-operation and Development. Classifying educational programmes: manual for ISCED-97 implementation in OECD countries. Paris: OECD; 1999.

42 Atkinson AB, Rainwater L, Smeeding TM. Income distribution in OECD countries: evidence from the Luxembourg Income Study (LIS). Paris: OECD Publishing; 1995.

43 Eurostat. Revision of the European Standard Population: Report of Eurostat's task force. 2013 edition. Luxembourg: European Union; 2013.

44 Wagstaff A, Paci P, van Doorslaer E. On the measurement of inequalities in health. Soc Sci Med. 1991;33(5): 545-57.

45 Harper S, King NB, Young ME. Impact of selective evidence presentation on judgments of health inequality trends: an experimental study. PLoS One. 2013 May;8(5):e63362.

46 Mackenbach JP, Kunst AE. Measuring the magnitude of socio-economic inequalities in health: an overview of available measures illustrated with two examples from Europe. Soc Sci Med. 1997 Mar;44(6):757-71.

47 Bross ID. How to use ridit analysis. Biometrics. 1958;14(1):18-38.

48 Harper S, Lynch J. Measuring health inequalities. In: Oakes JM, Kaufman JS, editors. Methods in social epidemiology. San Francisco: Jossey-Bass; 2006. p. 134-68.

49 Scholes S, Bajekal M, Love H, Hawkins N, Raine R, O’Flaherty M, et al. Persistent socioeconomic inequalities in cardiovascular risk factors in England over 1994-2008: a time-trend analysis of repeated cross-sectional data. BMC Public Health. 2012 Feb;12(1):129.

50 Marques-Vidal P, Bovet P, Paccaud F, Chiolero A. Changes of overweight and obesity in the adult Swiss population according to educational level, from 1992 to 2007. BMC Public Health. 2010 Feb;10(1):87.

51 Marques-Vidal P, Paccaud F, Ravasco P. Ten-year trends in overweight and obesity in the adult Portuguese population, 1995 to 2005. BMC Public Health. 2011 Oct;11(1):772.

52 Zhang Q, Wang Y. Trends in the association between obesity and socioeconomic status in U.S. adults: 1971 to 2000. Obes Res. 2004 Oct;12(10):1622-32.

53 Schneider S, Gruber J. Neighbourhood deprivation and outlet density for tobacco, alcohol and fast food: first hints of obesogenic and addictive environments in Germany. Public Health Nutr. 2013 Jul;16(7): 1168-77.

54 Hemphill E, Raine K, Spence JC, Smoyer-Tomic KE. Exploring obesogenic food environments in Edmonton, Canada: the association between socioeconomic factors and fast-food outlet access. Am J Health Promot. 2008 Jul-Aug;22(6):426-32.

55 Cummins SC, McKay L, MacIntyre S. McDonald's restaurants and neighborhood deprivation in Scotland and England. Am J Prev Med. 2005 Nov;29(4):308-10.

56 Macdonald L, Cummins S, Macintyre S. Neighbourhood fast food environment and area deprivation-substitution or concentration? Appetite. 2007 Jul;49(1):251-4

57 Reidpath DD, Burns C, Garrard J, Mahoney M, Townsend M. An ecological study of the relationship between social and environmental determinants of obesity. Health Place. 2002 Jun;8(2):141-5.

58 Giskes K, van Lenthe F, Avendano-Pabon M, Brug J. A systematic review of environmental factors and obesogenic dietary intakes among adults: are we getting closer to understanding obesogenic environments? Obes Rev. 2011 May;12(5):e95-106. 
Hoebel et al.: Socioeconomic Inequalities in Obesity Trends

59 Cummins S, Macintyre S. Food environments and obesity - neighbourhood or nation? Int J Epidemiol. 2006 Feb;35(1):100-4.

60 Macintyre S. Deprivation amplification revisited; or, is it always true that poorer places have poorer access to resources for healthy diets and physical activity? Int J Behav Nutr Phys Act. 2007 Aug;4(1):32.

61 Lange D, Wahrendorf M, Siegrist J, Plachta-Danielzik S, Landsberg B, Müller MJ. Associations between neighbourhood characteristics, body mass index and health-related behaviours of adolescents in the Kiel Obesity Prevention Study: a multilevel analysis. Eur J Clin Nutr. 2011 Jun;65(6):711-9.

62 Lakes T, Burkart K. Childhood overweight in Berlin: intra-urban differences and underlying influencing factors. Int J Health Geogr. 2016 Mar;15(1):12.

63 Abel T. Cultural capital and social inequality in health. J Epidemiol Community Health. 2008 Jul;62(7):e13.

64 Jordan S, Hoebel J. [Health literacy of adults in Germany: findings from the German Health Update (GEDA) study]. Bundesgesundheitsblatt Gesundheitsforschung Gesundheitsschutz. 2015 Sep;58(9):942-50. [In German].

65 Truman E, Lane D, Elliott C. Defining food literacy: a scoping review. Appetite. 2017 Sep; 116:365-71.

66 Hoebel J, Finger JD, Kuntz B, Kroll LE, Manz K, Lange C, et al. Changing educational inequalities in sporting inactivity among adults in Germany: a trend study from 2003 to 2012. BMC Public Health. 2017 Jun;17(1):547.

67 Taylor WC, Poston WS, Jones L, Kraft MK. Environmental justice: obesity, physical activity, and healthy eating. J Phys Act Health. 2006 Feb;3(s1):S30-54.

68 Bourdieu P. Distinction: a social critique of the judgement of taste. Cambridge: Harvard University Press; 1984.

69 Kim TJ, von dem Knesebeck O. Income and obesity: what is the direction of the relationship? A systematic review and meta-analysis. BMJ Open. 2018 Jan;8(1):e019862.

70 Prentice AM, Jebb SA. Beyond body mass index. Obes Rev. 2001 Aug;2(3):141-7.

71 Müller MJ, Bosy-Westphal A, Krawczak M. Genetic studies of common types of obesity: a critique of the current use of phenotypes. Obes Rev. 2010 Aug;11(8):612-8.

72 Bilger M, Kruger EJ, Finkelstein EA. Measuring Socioeconomic Inequality in Obesity: Looking Beyond the Obesity Threshold. Health Econ. 2017 Aug;26(8):1052-66.

73 Hoebel J, Kuntz B, Kroll LE, Finger JD, Zeiher J, Lange C, et al. Trends in absolute and relative educational inequalities in adult smoking since the early 2000s: the case of Germany. Nicotine Tob Res. 2018 Feb;20(3): 295-302.

74 Ernstsen L, Strand BH, Nilsen SM, Espnes GA, Krokstad S. Trends in absolute and relative educational inequalities in four modifiable ischaemic heart disease risk factors: repeated cross-sectional surveys from the NordTrøndelag Health Study (HUNT) 1984-2008. BMC Public Health. 2012 Apr;12(1):266.

75 Galobardes B, Costanza MC, Bernstein MS, Delhumeau C, Morabia A. Trends in risk factors for lifestyle-related diseases by socioeconomic position in Geneva, Switzerland, 1993-2000: health inequalities persist. Am J Public Health. 2003 Aug;93(8):1302-9.

76 Harper S, Lynch J. Trends in socioeconomic inequalities in adult health behaviors among U.S. states, 19902004. Public Health Rep. 2007 Mar-Apr;122(2):177-89.

77 Bambra CL, Hillier FC, Cairns JM, Kasim A, Moore HJ, Summerbell CD. How effective are interventions at reducing socioeconomic inequalities in obesity among children and adults? Two systematic reviews. Southampton (UK): NIHR Journals Library; 2015 Jan. (Public Health Research, No. 3.1.) Available from: https:// www.ncbi.nlm.nih.gov/books/NBK273911/.

78 Backholer K, Sarink D, Beauchamp A, Keating C, Loh V, Ball K, et al. The impact of a tax on sugar-sweetened beverages according to socio-economic position: a systematic review of the evidence. Public Health Nutr. 2016 Dec;19(17):3070-84.

79 Olstad DL, Teychenne M, Minaker LM, Taber DR, Raine KD, Nykiforuk CI, et al. Can policy ameliorate socioeconomic inequities in obesity and obesity-related behaviours? A systematic review of the impact of universal policies on adults and children. Obes Rev. 2016 Dec;17(12):1198-217. 